\title{
Solar Water Splitting by Semiconductor Nanocomposites and Hydrogen Storage with Quinoid Systems
}

\author{
Thorsten Wilke, Daniela Schricker, Josefin Rolf, Karl Kleinermanns* \\ Institute of Physical Chemistry, Heinrich-Heine-University, Duesseldorf, Germany \\ Email: *kleinermanns@uni-duesseldorf.de
}

Received August 6, 2012; revised September 7, 2012; accepted October 9, 2012

\begin{abstract}
Photocatalytic splitting of water was carried out in a two-phase system. The efficiencies of different types of nanocrystalline semiconductors were investigated and compared with commercialised $\mathrm{TiO}_{2}$ nanopowder. Generated hydrogen was chemically stored by use of a quinoid system, which seems to be useable for fuel cells. Solar light sensitive nanocomposites of $\mathrm{CdSe} / \mathrm{TiO}_{2}$ and $\mathrm{CdS}_{\mathrm{x}} \mathrm{Se}_{\mathrm{y}} / \mathrm{TiO}_{2}$ type were prepared and their good photocatalytic performance was demonstrated. In the visible range of $400-600 \mathrm{~nm} \mathrm{CdS}_{\mathrm{x}} \mathrm{Se}_{\mathrm{y}} / \mathrm{TiO}_{2}$ composites show comparable good results as in the UV range, which is very promising for their use as solar light water splitters. The concept of sensitising $\mathrm{TiO}_{2}$ with different kind of semiconductor nanoparticles, which is already known from quantum dot sensitised solar cells (QDSC), was demonstrated here for water splitting as well. Furthermore the kinetics of the storage reaction was investigated by UV-Vis spectroscopy and found to proceed via a consecutive reaction with an 1:1 charge transfer complex of quinone and hydroquinone as intermediate. The electron transfer process via a Fe $e^{2+} / \mathrm{Fe}^{3+}$ redox couple was investigated by $\mathrm{UV}$-Vis spectroscopy as well as by a dye reaction on the $\mathrm{TiO}_{2}$ surface. A light microscopic view of the surface of larger aggregates of $\mathrm{TiO}_{2}$ nanoparticles indicated different areas of photocatalytic activity with photocatalysis preferentially at catalyst edges. The global electron transfer process could be traced by following the dye colour in real time.
\end{abstract}

Keywords: Water Splitting; Nanocomposites; Cadmium Selenosulphide; Titanium Dioxide; Hydrogen Storage

\section{Introduction}

By the year 2050 the total energy consumption is expected to double, as the world's population is steadily increasing. Fossil fuels are not able to meet this energy demand in the long term, therefore, renewable energy resources will come more sharply into focus. The most promising alternative is solar light, because the amount of energy that arrives on earth every hour from the sun is greater than the amount that is required by the entire humanity in one year [1]. Yet, there is no practical way to transform and store this huge energy reserve efficiently, because the widely used silicon solar cells are of limited use here due to their high costs. Therefore it is necessary to look for less expensive and in sufficient quantities available alternatives to high-purity silicon. Storage of solar energy is possible for example by batteries and capacitors, but, compared to chemical bonds, these storage systems feature a low energy density. In this regard hydrogen is a good energy reservoir. It can be used as fuel for vehicles or can be converted into electrical energy by the use of fuel cells. The generation of hydrogen by electrolysis requires electrical energy, which could be ob-

\footnotetext{
${ }^{*}$ Corresponding author.
}

tained by use of solar cells, but the effectiveness is just approximately $8 \%$ for large-scale facilities [2]. Thus, direct photolytic water splitting by the use of suitable and inexpensive nanocrystalline semiconductors would be an promising alternative. Here the water is split without use of electricity and with high efficiency by solar light $[1,3]$.

The semiconductor titanium dioxide has a band gap of about $3 \mathrm{eV}$ and its conduction band potential is high enough for water splitting [4]. By absorption of photons electrons can be promoted to the excited state and electron-hole pairs are generated, which diffuse separately on the surface of the $\mathrm{TiO}_{2}$ particles:

$$
\mathrm{TiO}_{2}+h v \rightarrow \mathrm{e}^{-}+\mathrm{h}^{+}
$$

The formed holes in the valence band are able to oxidize molecules, for example water:

$$
\mathrm{H}_{2} \mathrm{O}+2 \mathrm{~h}^{+} \rightarrow \frac{1}{2} \mathrm{O}_{2}+2 \mathrm{H}^{+}
$$

The electrons in the conduction band can reduce species, for example $\mathrm{H}^{+}$to hydrogen because the reduction potential of $\mathrm{TiO}_{2}$ is sufficiently negative $(-0.65 \mathrm{~V}$ [5]):

$$
2 \mathrm{H}^{+}+2 \mathrm{e}^{-} \rightarrow \mathrm{H}_{2}
$$

For water splitting by $\mathrm{TiO}_{2}$ we finally obtain the fol- 
lowing overall reaction [6]:

$$
\mathrm{H}_{2} \mathrm{O}+2 h v \rightarrow \frac{1}{2} \mathrm{O}_{2}+\mathrm{H}_{2}
$$

Depending on the particle size, $\mathrm{TiO}_{2}$ nanoparticles (NPs) absorb at $<350$ - $380 \mathrm{~nm}$ [7]. Larger particles show smaller band gaps so that the absorption is red-shifted. Pure titanium dioxide can thus only use the UV part of the solar spectrum. However, most UV radiation is already absorbed by the ozone layer, which means that its fraction on earth is low. Therefore, extension of $\mathrm{TiO}_{2}$ 's light absorption to the visible region is of great interest. Depending on particle size cadmium selenide nanoparticles have a band gap of about $2.1 \mathrm{eV}$ [8] and absorb in the range up to $600 \mathrm{~nm}$ [9]. So by sensitization of titanium dioxide with cadmium selenide nanoparticles, a much better use of the solar spectrum is possible. An efficient electron injection from the photoexcited nanoparticle into the $\mathrm{TiO}_{2}$ conduction band requires a close contact, which can not be achieved by simple mixing of both semiconductors. Therefore we prepared nanocomposites by annealing a homogenous mixture of $\mathrm{TiO}_{2}$ and CdSe nanoparticles at $450^{\circ} \mathrm{C}$.

Cadmium selenosulphide $\mathrm{CdS}_{\mathrm{x}} \mathrm{Se}_{\mathrm{y}}$ are a novel class of photocatalysts. Their good ability as sensitizer in Quantum Dot Solar Cells (QDSC) has already been shown by our group. Their absorption depends strongly on the composition. The best results have been achieved with $\mathrm{CdS}_{6} \mathrm{Se}_{1}$ with an absorption up to $800 \mathrm{~nm}$ [7]. In principle, organic dyes can be used for sensitisation as well [10-12] and results obtained with this class of sensitisers for water splitting with solar light will be published elsewhere [13].

For the chemical storage of the generated hydrogen quinoid systems are suitable. Their use mimics natural processes, e.g. photosynthesis, which also use quinoid systems like plastoquinone for hydrogen transfer [6].

2,3-Dichloro-5,6-dicyano-1,4-benzoquinone (DDQ) is known from literature as a good hydrogen acceptor [14]. An advantage of this benzoquinone derivate is that DDQ and DDHQ are well distinguishable by UV-VIS spectroscopy allowing rather easy quantitative analysis. The constraint of using DDQ is its high reactivity towards water resulting in the evolution of hydrocyanic acid. Because of this behaviour the water splitting must be carried out in a two-phase system.

In 1999 Matsumura et al. presented a photocatalytic reaction system for splitting water by use of $\mathrm{TiO}_{2}$ nanoparticles [14]. The experimental setup consists of two compartments connected by an oil phase, which consists of DDQ and DDHQ dissolved in an organic solvent. The photocatalytic water splitting takes place in the first compartment containing $\mathrm{TiO}_{2}$ as photocatalyst in an aqueous iron(III) solution, where gaseous oxygen is generated. In the second compartment hydrogen is generated by use of platinum-loaded $\mathrm{TiO}_{2}$ nanoparticles in an aqueous bromine/bromide solution. DDQ/DDHQ serves as a hydrogen transporter between both compartments. The group of Matsumura has given a proof of principle; however, their hydrogen yields were very low and could be achieved only by very long and intense irradiation.

In this paper we present a further development of the scheme used in Ref. [14] and its extension to use visible solar light for photocatalysis. We compared $\mathrm{TiO}_{2}, \mathrm{CdSe}$ sensitised $\mathrm{TiO}_{2}$ and $\mathrm{CdS}_{6} \mathrm{Se}_{1}$ sensitised $\mathrm{TiO}_{2}$ for their efficiency of DDQ reduction by visible light. We also report investigations of the kinetics of the hydrogen storage reaction based on time-resolved UV-Vis investigations of DDQ conversion.

For a closer look at the processes on the surface of the nanocatalysts we recorded successive light microscopic images of $\mathrm{TiO}_{2}$ aggregates in an aqueous suspension. For visual detection of the electron transfer process a simple dye reaction was used, which verified a fast conversion of $\mathrm{Fe}^{3+}$ to $\mathrm{Fe}^{2+}$ on the surface of $\mathrm{TiO}_{2}$ aggregates. A magnification of the micrographs clearly visualised high active areas as bright spots on the surface of $\mathrm{TiO}_{2}$ nanoparticle aggregates.

\section{Experiments}

This article is dealing with the investigation of titanium dioxide, cadmium selenide and cadmium selenosulphide nanoparticles as well as nanocomposites of $\mathrm{TiO}_{2}$ with both semiconductors for their ability to split water photocatalytically.

\subsection{Preparation of the Photocatalysts}

Titanium dioxide nanopowder (Aerosil $\left.\mathrm{TiO}_{2} \mathrm{P}-25\right)$ was purchased by Degussa Evonik and used without any treatment.

Cadmium selenide nanoparticles are synthesised as follows [15]: $\mathrm{Cd}\left(\mathrm{ClO}_{4}\right)_{2} \cdot 6 \mathrm{H}_{2} \mathrm{O}(985 \mathrm{mg}, 2.35 \mathrm{mmol}$, Aldrich) was dissolved in $125 \mathrm{~mL}$ water. Afterwards 5.7 mmol of thioglycolic acid (TGA, Aldrich) as thiol-stabilizer were added during stirring and the $\mathrm{pH}$ of the solution was adjusted between 11.2 and 11.8 by dropwise addition of $1 \mathrm{M} \mathrm{NaOH}$ (Aldrich). A three neck flask with $\mathrm{Al}_{2} \mathrm{Se}_{3}$ lumps (134 mg, $0.46 \mathrm{mmol}$, Aldrich) was connected and flushed with $\mathrm{N}_{2}$ for about 30 minutes. The cadmium solution was deaerated in the same way. Subsequently $10-20 \mathrm{~mL}$ of $0.5 \mathrm{M} \mathrm{H}_{2} \mathrm{SO}_{4}$ (Aldrich) was added to the $\mathrm{Al}_{2} \mathrm{Se}_{3}$ lumps via a septum and the generated $\mathrm{H}_{2} \mathrm{Se}$ gas was passed to the solution via a slow nitrogen flow for about 20 minutes. The colour of the solution changed to orange due to the formation of CdSe particles. The $\mathrm{CdSe}$ precursors grew to CdSe nanoparticles under reflux $\left(100^{\circ} \mathrm{C}, 24\right.$ hours). For precipitation of the CdSe NCs, 
isopropanol (Fluka) was added. The suspension was centrifuged for 5 minutes at $13000 \mathrm{rmp}$, the aqueous phase was discarded and the residual solid was dried in an exsiccator for 1 week. This route gave particles with a size of $2-4 \mathrm{~nm}$.

As precursor for the preparation of cadmium selenosulphide nanoparticles, cadmium sulphide nanoparticles were prepared with a size distribution of 2 - $4 \mathrm{~nm}$ [16]. 1-thioglycerol (TG, $1.87 \mathrm{~mL}, 22 \mathrm{mmol}$, Aldrich) was added to $30 \mathrm{~mL}$ of a $80 \mathrm{mM}$ aqueous cadmium sulphate solution $\left(\mathrm{CdSO}_{4} \cdot 8 / 3 \mathrm{H}_{2} \mathrm{O}\right.$, Fluka). During constant stirring for 5 minutes ammonium sulphide (12.4 ml, 36 mmol, $20 \%$ aqueous solution, Aldrich) was added. An intense yellow solution with yellow precipitation was obtained thereafter, which was centrifuged and dried for 1 week in an exsiccator.

Cadmium selenosulphide nanocomposites were prepared as follows: In a specific molar ratio of 6:1 (S:Se) cadmium sulphide nanoparticles and selenium powder $(99.5 \%$, Aldrich) were suspended in methanol. After 1 hour of stirring the methanol was evaporated at $80^{\circ} \mathrm{C}$. The resulting CdS:CdSe solid was sintered at $550^{\circ} \mathrm{C}$ for 15 minutes. The colour of the remaining $\mathrm{CdS}_{6} \mathrm{Se}_{1}$ nanocomposite is intensive red.

$\mathrm{CdS}_{6} \mathrm{Se}_{1}$ is not soluble in common solvents, which precludes their direct TEM investigation. The $\mathrm{CdS}_{6} \mathrm{Se}_{1}$ nanoparticles were absorbed on the surface of small $\mathrm{TiO}_{2}$ nanoparticles by mixing the finely grinded solid with a clear and colourless solution of $\mathrm{TiO}_{2}$ nanoparticles. The resulting nanocomposites could be investigated by TEM and elementary analysis by EDX showed their composition.

The clear and colourless solution of $\mathrm{TiO}_{2}$ nanoparticles was prepared as follows [17]: titanium (IV) butoxide (8.5 $\mathrm{mL}, 0.025 \mathrm{mmol}$, Aldrich) was dissolved in ethanol (19 $\mathrm{mL}$, Aldrich) and diethanolamine $(2 \mathrm{~mL}, 20.8 \mathrm{mmol}$, Fluka). Subsequently $19 \mathrm{~mL}$ ethanol and $0.5 \mathrm{~mL} \mathrm{H}_{2} \mathrm{O}$ were added very slowly. The solution was stirred over night.

$\mathrm{CdSe} / \mathrm{TiO}_{2}$ respectively $\mathrm{CdS}_{6} \mathrm{Se}_{1} / \mathrm{TiO}_{2}$ nanocomposites were prepared by mixing with a suitable $\mathrm{TiO}_{2}$ paste. $\mathrm{TiO}_{2}$ nanopowder (5 g Aearosil $\mathrm{TiO}_{2} \mathrm{P} 25$, Evonik) was suspended in nitric acid ( $1 \mathrm{~N}$, Fluka). This suspension was heated at $80^{\circ} \mathrm{C}$ for 24 hours. Afterwards the nitric acid was evaporated and the $\mathrm{TiO}_{2}$ solid was dried for 3 days at $100^{\circ} \mathrm{C}$. Finally the $\mathrm{TiO}_{2}$ solid was treated with $25 \mathrm{ml}$ water, acetylacetone (2.5 g, $24.97 \mathrm{mmol}$, Merck), Triton-X100 (1.25 g, $1.92 \mathrm{mmol}$, Avocado) and polyethylene oxide (M.W. 100000, Alfa Aesar) to give a homogenous paste. $40 \mathrm{mg}$ of $\mathrm{CdSe}$ or $\mathrm{CdS}_{6} \mathrm{Se}_{1}$ were mixed with $1 \mathrm{~mL}$ of this $\mathrm{TiO}_{2}$ suspension in an agate mortar to produce a smooth and uniformly coloured paste, which was dried in a ceramic crucible at $80^{\circ} \mathrm{C}$ for 2 hours. Afterwards the solid was sintered at $450^{\circ} \mathrm{C}$ in a muffle furnace for about
30 minutes and ground to a fine powder.

\subsection{Photocatalytic Water Splitting}

2,3-Dichloro-5,6-dicyano-1,4-benzoquinone (98\%, Aldrich), iron(III) chloride ( $>97 \%$, Aldrich) and n-butyronitrile (purum, $\geq 99.0 \%$, Fluka) was used without purification.

The water splitting experiments were carried out in a quartz cuvette of $2 \times 4 \times 4 \mathrm{~cm}$ size. $30 \mathrm{mg}$ of the photocatalyst were dispersed in $16 \mathrm{~mL}$ of an aqueous iron (III) chloride solution $(8.0 \mathrm{mM}) .5 \mathrm{~mL}$ of a DDQ solution in n-butyronitrile $(1.9 \mathrm{mM})$ was placed carefully on top of the aqueous phase to form the organic phase. In order to avoid an evaporation of the organic solvent, the cuvette was covered by a glass plate of adequate size. To avert heating of the reaction system during irradiation and to reduce diffusion of DDQ into the aqueous phase, the vessel was cooled to $15^{\circ} \mathrm{C}$ by a water flushed aluminium block, connected to the cuvette by a heat-conductive paste.

The irradiation was carried out for 90 minutes by a $80 \mathrm{~W}$ mercury-vapor lamp (Oriel, Germany), which was mildly focused to give $100 \mathrm{~mW} / \mathrm{cm}^{2}$.

To prevent irradiation of the organic phase and photodegradation of DDQ and DDHQ an aluminium mask of adequate size was used.

For investigation of the efficiency of the photocatalysts in the range of the visible solar spectrum, the water splitting experiment was performed by irradiation of the aqueous phase with the unfiltered $\mathrm{Hg}$ lamp spectrum and, for comparison, with a filtered lamp spectrum (400 - 600 $\mathrm{nm}$ ). For this purpose a suitable cut-off filter (Edmund optics $\mathrm{GmbH}$, Karlsruhe) was placed between lamp and reaction vessel.

To exclude contributions to the spectra, which were not due to the process of water splitting, a reference solution of the organic phase was kept in the dark without contact to the aqueous phase during irradiation.

After 90 min irradiation a sample of the organic phase was taken, diluted 1:25 with n-butyronitrile and analysed by UV-Vis spectroscopy.

\subsection{Kinetics of the Hydrogen Storage Reaction}

The water splitting experiment described above was carried out with $30 \mathrm{mg}$ of $\mathrm{P}-25 \mathrm{TiO}_{2}$. Irradiation of the aqueous phase was performed over 100 minutes with the unfiltered $\mathrm{Hg}$ lamp spectrum $\left(100 \mathrm{~mW} / \mathrm{cm}^{2}\right)$. Every 10 minutes a $100 \mu \mathrm{L}$ sample of the organic phase was taken at exactly the same position via a rigidly adjusted stainless steal cannula. The samples were diluted 1:25 with n-butyronitrile and analysed by UV-Vis spectroscopy. The recorded spectra were processed by a peak analysing software (OriginPro 8G, OriginLab Coopera- 
tion, USA) to determine the exact absorption of the involved species and the change of their concentrations with reaction time.

\subsection{Tracking of the Electron Transport Process via UV-Vis Spectroscopy}

For tracking the electron transport process via $\mathrm{Fe}^{3+} / \mathrm{Fe}^{2+}$ the aqueous phase was investigated by UV-Vis spectroscopy as well. A suspension of titanium dioxide nanoparticles in water shows strong light scattering, so that the kinetic analysis can not be performed with $\mathrm{TiO}_{2}$ as photocatalyst. Therefore CdSe in a 10 times lower concentration $(1 \mathrm{mg}$, dissolved in $16 \mathrm{~mL}$ of a $8.0 \mathrm{mM}$ aqueous $\mathrm{FeCl}_{3}$ solution) was used, which also photocatalytically splits water. Irradiation of the aqueous phase was performed for 90 minutes with an unfiltered $\mathrm{Hg}$ lamp spectrum $\left(100 \mathrm{~mW} / \mathrm{cm}^{2}\right)$. Every 15 minutes a $100 \mu \mathrm{L}$ sample of the aqueous phase was taken at exactly the same position via a rigidly adjusted stainless steal cannula. The samples were again analysed by UV-Vis spectroscopy to follow the reduction of $\mathrm{Fe}^{3+}$ to $\mathrm{Fe}^{2+}$ quantitatively.

\subsection{Visual Detection of the Electron Transfer Process via a Dye Reaction}

About $1 \mathrm{~mL}$ of a suspension of $30 \mathrm{mg} \mathrm{P}-25 \mathrm{TiO}_{2}$ nanoparticles in $16 \mathrm{~mL}$ of an aqueous solution of iron (III) chloride $(8 \mathrm{mM})$ and potassium ferrocyanide(III) $(8 \mathrm{mM})$ was placed on a glass slide. The slide was positioned under a light microscope and consecutive light microscopic images were taken at 500-times magnification while the sample was irradiated for 5 minutes by a $80 \mathrm{~W}$ Hg-Lamp. Bright spots from Prussian blue $\mathrm{K}\left[\mathrm{Fe}^{\mathrm{III}} \mathrm{Fe}^{\mathrm{II}}(\mathrm{CN})_{6}\right]$ indicate the positions of $\mathrm{Fe}^{3+}$ reduction on the surface of the $\mathrm{TiO}_{2}$ aggregates.

\subsection{Experimental Equipment}

The particle size distribution of the photocatalyst nanoparticles was investigated by Transmission Electron Microscopy (TEM) measurements, which were performed with a HITACHI TEM 7500 microscope equipped with a Mega View II camera (Soft Imaging System) at the MaxPlanck institute for coal research (MPI Mülheim a.d. Ruhr).

$\mathrm{TiO}_{2}$ nanopowder has been obtained as a commercialised product from Degussa Evonik and was used without treatment. To verify the given properties Transmission Electron Microscopy (TEM) images has been taken. They are shown in Figure SI1. An average particle size of $21 \mathrm{~nm}$ and a homogeneous size distribution have been found.

Optical absorption spectra of the organic phase were recorded by using a Cary $300 \mathrm{UV}$-Vis spectrophotometer operated at a resolution of $1 \mathrm{~nm}$.

Light microscopic images have been taken by using an Olympus BX41M reflected-light microscope and an Aiptec AHD 720P digital camcorder.

\section{Results and Discussion}

Our experimental setup is shown in Figure 1. A solution of DDQ in n-butyronitrile forms the organic layer and is located above the aqueous phase, in which the water splitting takes place. A Fe ${ }^{2+}-\mathrm{Fe}^{3+}$ redox system transports the electrons between the two phases. The holes in the valence band of titanium dioxide oxidize water, while the excited electrons in the conduction band reduce the $\mathrm{Fe}^{3+}$ to $\mathrm{Fe}^{2+}$ ions. The reduced iron ions transport electrons to the interface, where quinone is subsequently reduced to semihydroquinone and hydroquinone by accepting electrons from $\mathrm{Fe}^{2+}$ and protons from water. Because of the spatial separation of reduction and oxidation processes in two different phases, electron-hole recombination can be minimized and the oxidation of DDHQ by $\mathrm{TiO}_{2}$-holes can be prevented. By this, a quantitative DDQ to DDHQ conversion can be realized.

The redox scheme in Figure 2 confirms the energetic feasibility of this approach.

DDQ shows a strong absorption band with a maximum at $278 \mathrm{~nm}$, while DDHQ shows absorption bands at 248 and $347 \mathrm{~nm}$ (Figure 3).

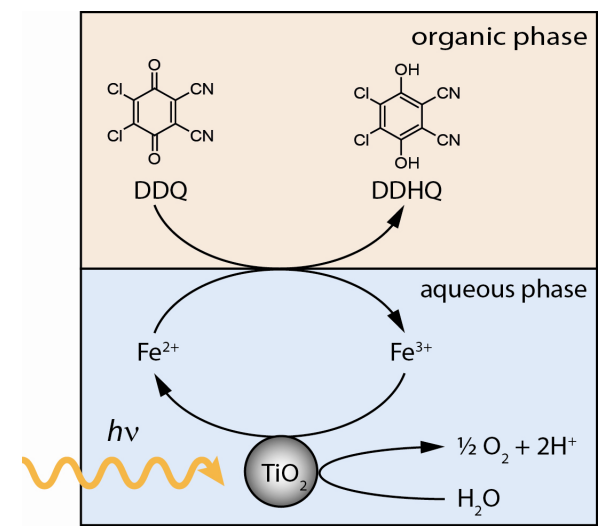

Figure 1. Experimental setup of the two-phase system. The photocatalyst nanopowder, e.g. $\mathrm{TiO}_{2}$, is suspended in a solution of $\mathrm{FeCl}_{3}$ in water which forms the aqueous phase. It is covered with a layer of the organic phase, a solution of 2,3-Dichloro-5,6-dicyano-1,4-benzoquinone (DDQ) in n-butyronitrile [14]. The reaction cell is tempered by a water cooling block to approximately $15^{\circ} \mathrm{C}$ to reduce diffusion of DDQ into the aqueous phase. The aqueous phase is irradiated by a Hg lamp, which is mildly focused to give 100 $\mathrm{mW} / \mathrm{cm}^{2}$. Aluminium foil prevents irradiation of the organic phase. The $\mathrm{TiO}_{2}$ nanoparticles are coated with CdSe or $\mathrm{CdS}_{6} \mathrm{Se}_{1}$ nanoparticles for sensitisation to solar light (not shown in the figure). 


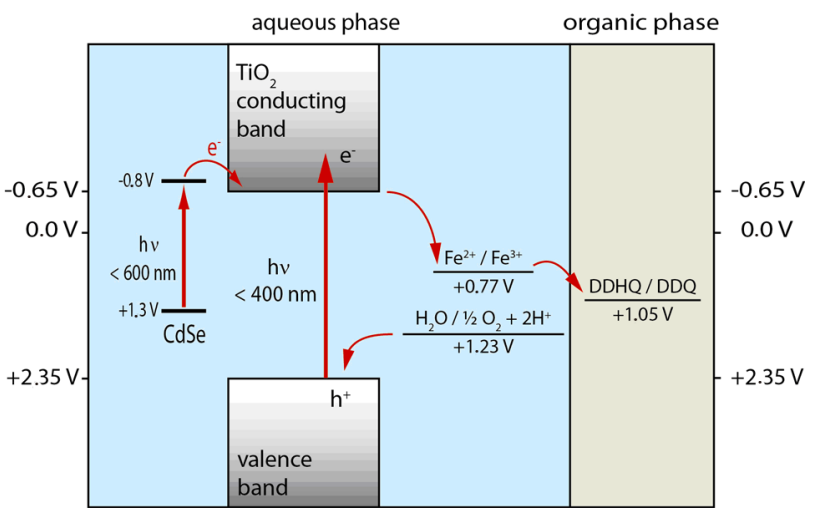

Figure 2. Energy scheme of the two-phase water splitting experiment. Redox potentials are given in Volts [V] against Standard Hydrogen Potential [SHE]. The working principle is based on excitation of the photocatalyst, e.g. $\mathrm{TiO}_{2}$. The excited electron $\left(\mathrm{e}^{-}\right)$is stored by reducing $\mathrm{Fe}^{3+}$ to $\mathrm{Fe}^{2+}$ and transported to the interphase by diffusion. The electron transporter is regenerated to $\mathrm{Fe}^{3+}$ by reducing DDQ. Holes $\left(h^{+}\right)$in the valence band are filled by oxidation of water leading to $\mathrm{O}_{2}$ and $\mathrm{H}^{+}$. DDHQ is formed at the interface by reaction of $\mathrm{H}^{+}$with the reduced DDQ.

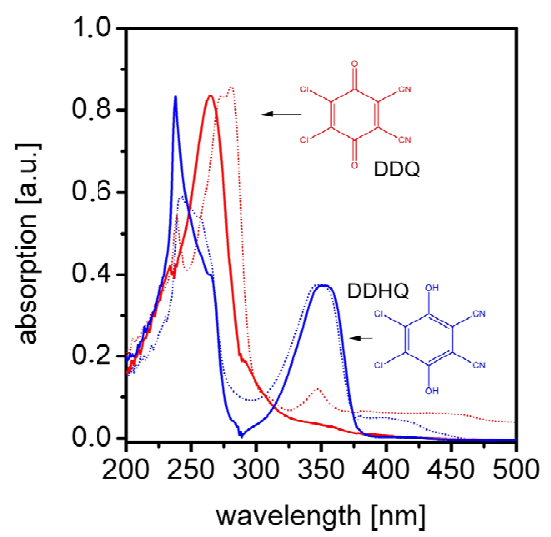

Figure 3. UV-Vis spectra of DDQ (red) and DDHQ (blue) measured in THF (solid curves) and n-butyronitrile (dotted curves). The spectra were obtained using a suprasil quartz cell with $1 \mathrm{~cm}$ path length and a double-beam UV-Vis spectrophotometer operated at a resolution of $1 \mathrm{~nm}$.

Figure 4(a) displays a TEM image of synthesized CdSe nanoparticles stabilised with thioglycolic acid (TGA). A narrow size distribution has been found and is presented in the inset. Typical size ranges are $2-4 \mathrm{~nm}$. Based on our TEM images we propose Ostwald ripening to be responsible for the formation of the nanoparticles.

A TEM image of the $\mathrm{CdS}_{6} \mathrm{Se}_{1}$ nanocomposite in contact with $\mathrm{TiO}_{2}$ is displayed in Figure 4(b). The composite particles show an average size of $50 \mathrm{~nm}$. Elemental analysis by local Energy Dispersive X-ray spectroscopy (EDX) indeed showed that the composite particles contain Ti, Cd, S and Se.

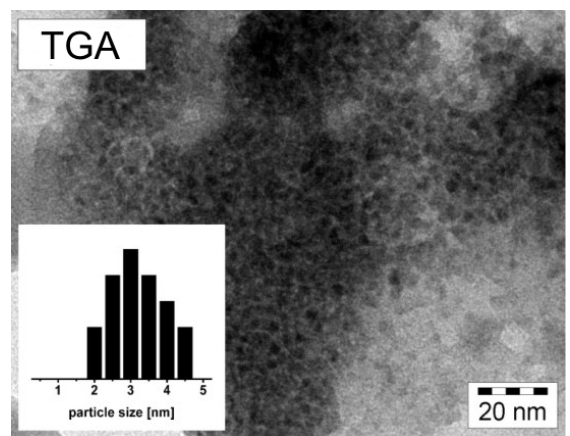

(a)

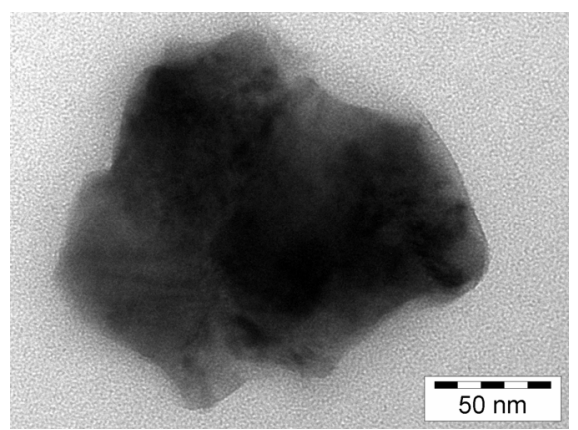

(b)

Figure 4. (a) TEM images of CdSe nanoparticles stabilised with thioglycolic acid (TGA). The synthesis is described in the experimental section. The insets indicate the size distribution as obtained from diameter measurements of 20 - 40 particles. Typical size ranges are 2 - $4 \mathrm{~nm}$; (b). TEM image of $\mathrm{CdS}_{\mathrm{x}} \mathrm{Se}_{\mathrm{y}} / \mathrm{TiO}_{2}$ nanocomposites obtained from dispersion of $\mathrm{CdS}_{\mathrm{x}} \mathrm{Se}_{\mathrm{y}}$ particles in a colourless, clear $\mathrm{TiO}_{2}$ solution.

The results of the water splitting experiments are presented in Figures SI2-SI4 and Figure 5(a). Compared are the UV-Vis spectra of the diluted organic phase after 90 minutes irradiation with the unfiltered $\mathrm{Hg}$ lamp spectra and a filtered Hg lamp spectrum (400 - $600 \mathrm{~nm}$ ). Irradiation for $<90$ minutes shows a significant slower conversion of DDQ to DDHQ when using the filtered $\mathrm{Hg}$ lamp and $\mathrm{TiO}_{2}, \mathrm{TiO}_{2} / \mathrm{CdSe}$ or CdSe photocatalyst. The conversion of DDQ to DDHQ proceeds via an intermediate 1:1 complex of DDQ and DDHQ. The reaction process can be described as follows:

DDHQ is formed by reduction of DDQ and acceptance of two protons.

$$
\mathrm{DDQ}+2 \mathrm{e}^{-}+2 \mathrm{H}^{+} \rightarrow \mathrm{DDHQ}
$$

A 1:1 charge-transfer complex is formed with remaining DDQ.

$$
\mathrm{DDQ}+\mathrm{DDHQ} \rightarrow[\mathrm{DDQ} \cdot \mathrm{DDHQ}]
$$

The complex is degraded by reducing and accepting two further protons and electrons to obtain two DDHQ molecules.

$$
[\mathrm{DDQ} \cdot \mathrm{DDHQ}]+2 \mathrm{e}^{-}+2 \mathrm{H}^{+} \rightarrow 2 \mathrm{DDHQ}
$$




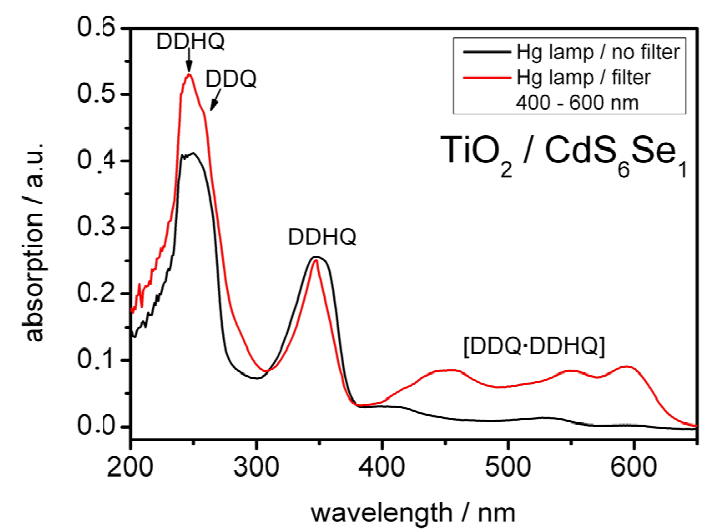

(a)

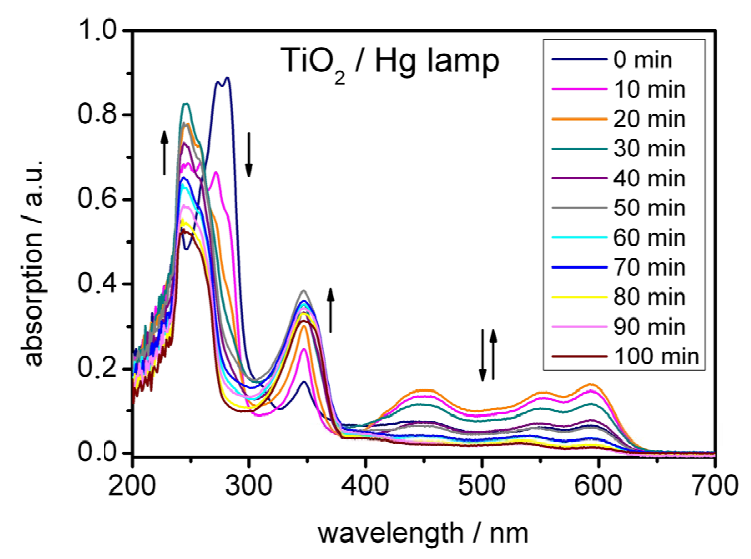

(b)

Figure 5 (a) Water splitting by $\mathrm{TiO}_{2} / \mathrm{CdS}_{6} \mathrm{Se}_{1}$ nanocomposites as photocatalyst. Shown are the UV-Vis spectra of the organic phase after 90 minutes reaction time. The black line shows the conversion of DDQ to DDHQ after 90 minutes irradiation of the aqueous phase with the unfiltered $\mathrm{Hg}$ lamp spectrum. The red line shows the result after $90 \mathrm{mi}-$ nutes irradiation with a filtered lamp spectrum $(400-600$ $\mathrm{nm})$ by using an optical glass filter. The recorded absorption bands can be assigned to three different species: DDQ (absorption at $278 \mathrm{~nm}$ ), DDHQ (absorption at $248 \mathrm{~nm}, 347$ $\mathrm{nm}$ ) and complexed [DDQ·DDHQ] (absorption at $448 \mathrm{~nm}$, $509 \mathrm{~nm}, 552 \mathrm{~nm}, 593 \mathrm{~nm})$. The remaining DDQ and [DDQ-DDHQ] indicates the achieved conversion of DDQ and is a measure of the efficiency of the used photocatalyst for water splitting and hydrogen storage; (b) Temporal progress of the conversion reaction DDQ to DDHQ. Shown are the UV-Vis spectra of the organic phase measured over 100 minutes. The recorded absorption bands can be assigned to three different species: DDQ (absorption at 278 $\mathrm{nm}$ ), DDHQ (absorption at $248 \mathrm{~nm}, 347 \mathrm{~nm}$ ) and complexed [DDQ·DDHQ] (absorption at $448 \mathrm{~nm}, 509 \mathrm{~nm}, 552 \mathrm{~nm}, 593$ $\mathrm{nm})$. Increase and decrease of absorption bands are indicated by arrows. A decrease of the DDQ concentration and a simultaneous increase of the DDHQ concentration with time can be observed. Complexed [DDQ.DDHQ] is formed as an intermediate, whose absorption quickly emerges, increases within 20 minutes, afterwards decreases and completely vanishes after 80 minutes. The absence of isosbestic points indicates at least one further intermediate in the course of the reaction.
The observed absorption bands, shown in Figure SI2SI4 and Figure 5(a), can be assigned to these three different species. DDQ shows a strong absorption at $278 \mathrm{~nm}$, whereas DDHQ has two different absorption bands at $248 \mathrm{~nm}$ and $347 \mathrm{~nm}$. Therefore the absorption bands of educt and product can be distinguished. The intermediate charge-transfer complex [DDQ·DDHQ] exhibits a wide absorption in the range of $400-650 \mathrm{~nm}$ with absorption maxima at $448 \mathrm{~nm}, 509 \mathrm{~nm}, 552 \mathrm{~nm}$ and $593 \mathrm{~nm}$. Efficient photocatalytic water splitting process and hydrogen storage by quinine reduction is indicated by a complete conversion of DDQ into DDHQ without remaining [DDQ·DDHQ] complex. The observed absorption of remaining free and complexed DDQ is a measure of the efficiency of the photocatalyst and the hydrogen storage system. Considering that the irradiation of the earth by the sun has only a small UV component, the performance of the catalyst using the visible part of the sun spectrum is of particular interest. This has been investigated by using a filtered $\mathrm{Hg}$ lamp spectrum in the range of $400-600$ $\mathrm{nm}$. The resulting spectrum is displayed as red line in Figure SI2-SI4 and Figure 5(a). The black line shows the absorption of the organic phase after irradiation of the aqueous phase with the unfiltered lamp spectrum.

Figure SI2 summarises the performance of $\mathrm{TiO}_{2}$ nanoparticles without sensitiser. It can clearly be seen that the efficiency of $\mathrm{TiO}_{2}$ in the visible range is very low. A strong absorption at $278 \mathrm{~nm}$ indicates a large amount of unconverted DDQ while the observed absorption bands of DDHQ at $248 \mathrm{~nm}$ and $347 \mathrm{~nm}$ are, compared with the result of the unfiltered irradiation, rather small. Weak absorptions at $448 \mathrm{~nm}, 509 \mathrm{~nm}, 552 \mathrm{~nm}$ and $593 \mathrm{~nm}$ are referring to a small [DDQ·DDHQ] complex concentration.

The performance of CdSe nanoparticles under the same conditions is presented in Figure SI3. For irradiation with a strong UV component a comparably good performance as $\mathrm{TiO}_{2}$ could be demonstrated. Due to its absorption up to $600 \mathrm{~nm}$ the efficiency in the visible range is significantly higher compared to $\mathrm{TiO}_{2}$. Nevertheless a complete DDQ conversion could not be achieved, which is clearly evident from the observed absorption of unconverted DDQ and complexed DDQ.

Quite contrary to these results, nanocomposites of titanium dioxide and cadmium selenide, characterised by a very close contact between both semiconductors, behave quite differently. Our results are given in Figure SI4. Even though a strong absorption in the range of 400 $650 \mathrm{~nm}$ indicates a quite high complex concentration, the conversion of DDQ to DDHQ is higher compared to the exclusive use of CdSe.

This strategy to combine $\mathrm{TiO}_{2}$ with its excellent properties for water splitting with a sensitising semiconductor for good absorption in the visible range is very pro- 
mising. The efficiency can be further enhanced by using $\mathrm{CdS}_{6} \mathrm{Se}_{1}$ in close contact with $\mathrm{TiO}_{2}$. The performance of this $\mathrm{TiO}_{2} / \mathrm{Cd}_{6} \mathrm{Se}_{1}$ nanocomposite is shown in Figure 5(a).

Compared to $\mathrm{TiO}_{2} / \mathrm{CdSe}$ the efficiency is significantly higher. Even though [DDQ·DDHQ] can still be observed, its concentration is lower than the concentration, which was found by using $\mathrm{TiO}_{2}, \mathrm{CdSe}$ or $\mathrm{TiO}_{2} / \mathrm{CdSe}$ for visible light catalysis. Taking the high concentration of formed DDHQ in account it can be clearly concluded that the conversion reaction is already far proceeded.

The progress of the conversion reaction from DDQ to DDHQ with time was studied via UV-Vis investigations of the organic phase as function of time for 100 minutes. The UV-Vis spectra are shown in Figure 5(b). The observed absorption bands can be assigned to the three species DDQ (278 nm), DDHQ (248 nm, $347 \mathrm{~nm})$ and [DDQ·DDHQ] (448 nm, $509 \mathrm{~nm}, 552 \mathrm{~nm}, 593 \mathrm{~nm})$. The mechanism of the conversion reaction is described above. The spectra indicate a fast degradation of DDQ and a corresponding increase of [DDQ - DDHQ] as intermediate. After 20 minutes the absorption of complexed DDQ starts to decrease for about 1 hour until it is completely reduced to DDHQ. The absorption of DDHQ is found to increase simultaneously with the decrease of DDQ.

Based on these UV-Vis measurements the kinetics of the conversion reaction was assigned. The kinetic curves are presented in Figure 6. The temporal course is typical for a consecutive reaction. Contrary to our expectations a small decrease of the DDHQ concentration was observed at the end of the reaction. This can be explained as the result of a number of minor side reactions, which leads to loss of DDHQ, for example diffusion of DDHQ into the aqueous phase, photochemical degradation due to light scattering by the photocatalyst particles into the organic phase and/or hydrolysis of DDHQ at the interphase. Therefore we do not obtain a 100\% mass balance. A small quantity of DDHQ and [DDQ - DDHQ] was observed before irradiation which seems to be formed by a side reaction. This portion was assumed to be constant during irradiation and therefore subtracted from the measured concentrations.

The results of our UV-Vis studies of the aqueous phase during the irradiation process are shown in Figure SI5. The electron transport via the redox couple $\mathrm{Fe}^{3+} / \mathrm{Fe}^{2+}$ from the surface of the excited photocatalyst through the aqueous phase to the interface was tracked over 90 minutes. Due to an overlap of the absorption bands of $\mathrm{Fe}^{3+}$ and $\mathrm{Fe}^{2+}$ the absorption of $\mathrm{Fe}^{2+}$ can just be found as a shoulder in the absorption band of $\mathrm{Fe}^{3+}$. For comparison the absorption maxima of $\mathrm{Fe}^{3+}$ and $\mathrm{Fe}^{2+}$ are indicated by arrows. A rapid decrease of the $\mathrm{Fe}^{3+}$ absorption was observed with irradiation time.

At $\sim 90$ min the $\mathrm{Fe}^{2+} / \mathrm{Fe}^{3+}$ concentration ratio does not change anymore with time (concentration equilibrium) because $\mathrm{Fe}^{2+}$ is not consumed anymore for DDQ reduction (nearly complete conversion to DDHQ).

Figures 7 and SI6 gives a more detailed, spatially resolved view of the electron transfer at the surface of photoexcited $\mathrm{TiO}_{2}$. The transfer process was followed by a simple dye reaction. After irradiation an electron is transferred from the surface of an excited $\mathrm{TiO}_{2}$ particle to an iron(III) ion to form an iron(II) ion, which is immediately trapped by potassium ferrocyanide(III). The so formed complex $\mathrm{K}\left[\mathrm{Fe}^{\mathrm{III}} \mathrm{Fe}^{\mathrm{II}}(\mathrm{CN})_{6}\right]$ is well-know as a stable and intensive blue coloured dye called Prussian blue. In our experiment it was used as a visual detector for the formation of $\mathrm{Fe}^{2+}$ at the surface of photoexcited $\mathrm{TiO}_{2}$ particles. The dye reaction was followed by use of a light microscope. As single $\mathrm{TiO}_{2}$ nanoparticles are much too small to be observable by light microscopic magnification, aggregates of $\mathrm{TiO}_{2}$ nanoparticles with a size of 10 - $15 \mu \mathrm{m}$ were used. The aggregates were formed by using a particularly highly concentrated $\mathrm{TiO}_{2}$ suspension. Within the first two minutes a green and turquoise colour appears, which is due to a mixture of the yellow-orange

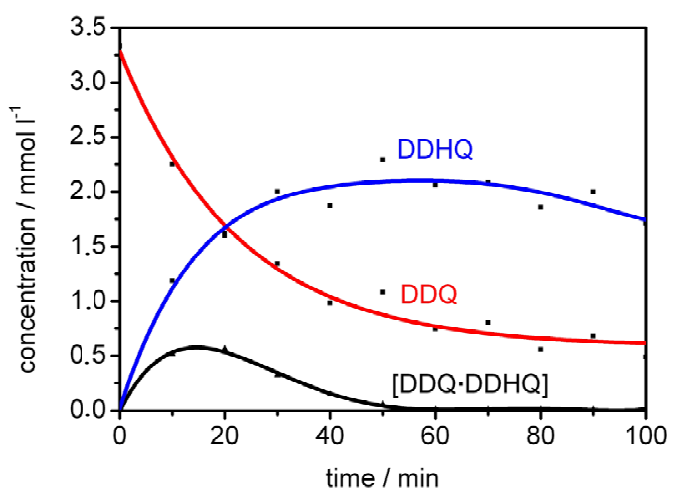

Figure 6. Kinetics of the hydrogen storage reaction. Illustrated are the time-depenent changes in concentration of DDQ (red), DDHQ (blue) and [DDQ·DDHQ] complex (black). The shown kinetic curves are based on UV-Vis measurements of the organic phase for 100 minutes; see Figure 5(b). The kinetics complies with a typical consecutive reaction.

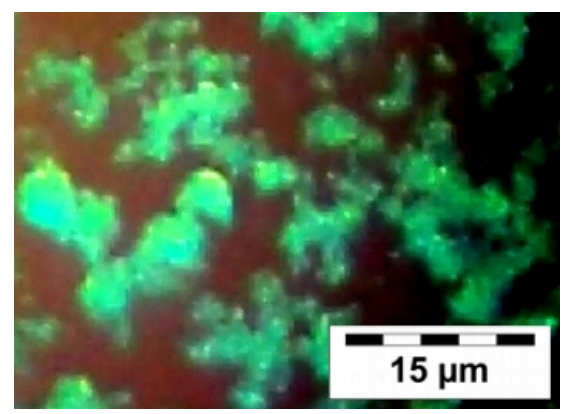

Figure 7. Enlarged detail of the light optical micrograph, see Figure SI6. Bright spots on the surface of the aggregated $\mathrm{TiO}_{2}$ nanoparticles are clearly visible and indicate highly active areas. 
colour of remaining $\mathrm{FeCl}_{3}$ and the blue colour of already formed Prussian blue. After 5 minutes of irradiation the surface of the $\mathrm{TiO}_{2}$ aggregates appears intensive blue coloured, see Supplementary Information.

It can be assumed that the surface of the $\mathrm{TiO}_{2}$ aggregates is rough with different kind of edges. An enlargement of the light optical micrograph, which is presented in Figure 7, indicates high active reaction areas, which are visible as bright spots on the surface of the $\mathrm{TiO}_{2}$ aggregates, mostly near edges. Edges therefore appear to be the areas of higher photoreduction activity.

\section{Conclusion}

We presented an experimental setup to investigate the performance of nanocrystalline semiconductors for photocatalytic water splitting. Chemical storage of the generated hydrogen by quinoid systems seems to be a good alternative to evolution of gaseous $\mathrm{H}_{2}$ as it is easy to handle and can be use as recyclable fuel for fuel cells, as we show in a further publication [18].

\section{Acknowledgements}

The authors gratefully acknowledge Dr. Christian W. Lehmann and his group (Max-Planck Institut für Kohlenforschung, Mülheim/Ruhr) for the implementation of the TEM measurements and Dr. Daniel Ogermann (Institute of Physical Chemistry, Heinrich-Heine-University, Düsseldorf) for his assistance in preparation of the photocatalyst samples.

\section{REFERENCES}

[1] R. Pike and P. Earis, "Powering the World with Sunlight," Energy \& Enviromental Science, Vol. 3, No. 2, 2010, p. 173. doi: $10.1039 / \mathrm{b} 924940 \mathrm{k}$

[2] N. Kelly, T. Gibson and D. Ouwerkerk, "Generation of High-Pressure Hydrogen for Fuel Cell Electric Vehicles Using Photovoltaic-Powered Water Electrolysis," International Journal of Hydrogen Energy, Vol. 36, No. 24, 2011, pp. 15803-15825.

doi:10.1016/i.ijhydene.2011.08.058

[3] E. Durgun, S. Ciraci, W. Zhou and T. Yildirim, "Transition-Metal-Ethylene Complexes as High-Capacity Hydrogen-Storage Media," Physical Review Letters, Vol. 97, No. 22, 2006, pp. 1-4. doi:10.1103/PhysRevLett.97.226102

[4] M. Grätzel, "Photoelectrochemical Cells," Nature, Vol. 414, No. 6861, 2001, pp. 338-344. doi:10.1038/35104607

[5] A. Hagfeldt and M. Grätzel, "Light-Induced Redox Reactions in Nanocrystalline Systems," Chemical Reviews, Vol. 95, No. 1, 1995, pp. 49-68.

\section{doi:10.1021/cr00033a003}

[6] M. Kaneko and I. Okura, "Photocatalysis-Science and Technology," Springer, Heidelberg, 2002.

[7] D. Ogermann, T. Wilke and K. Kleinermanns, " $\mathrm{CdS}_{\mathrm{x}} \mathrm{Se}_{\mathrm{y}} /$ $\mathrm{TiO}_{2}$ Solar Cell Prepared with Sintered Mixture Deposition," Open Journal of Physical Chemistry, Vol. 2, No. 1, 2012, pp. 47-57. doi:10.4236/ojpc.2012.21007

[8] D. R. Cooper and N. M. Dimitrijevic, "Photosensitization of CdSe/ZnS QDs and Reliability of Assays for Reactive Oxygen Species Production," Nanoscale, Vol. 2, No. 1, 2010, pp. 114-121. doi:10.1039/b9nr00130a

[9] I. Robel, M. Kuno and P. V. Kamat, "Size-Dependent Electron Injection from Excited CdSe Quantum Dots into $\mathrm{TiO}_{2}$ Nanoparticles," Journal of the American Chemical Society, Vol. 129, No. 14, 2007, pp. 4136-4137. doi: $10.1021 / \mathrm{ja} 070099 \mathrm{a}$

[10] M. Grätzel, "Dye-Sensitized Solar Cells," Journal of Photochemistry and Photobiology C, Vol. 4, No. 2, 2003, pp. 145-153. doi:10.1016/S1389-5567(03)00026-1

[11] T. Meyer, D. Ogermann, A. Pankrath, K. Kleinermanns and T. J. J. Müller, "Phenothiazinyl Rhodanylidene Merocyanines for Dye-Sensitized Solar Cells," The Journal of Organic Chemistry, Vol. 77, No. 8, 2012, pp. 3704-3715. doi:10.1016/10.1021/jo202608w

[12] R. Menzel, D. Ogermann, S. Kupfer, D. Weib, H. Görls, K. Kleinermanns, L. González and R. Beckert, "4-Methoxy-1,3-thiazole Based Donor-Acceptor Dyes: Characterization, X-Ray Structure, DFT Calculations and Test as Sensitizers for DSSC," Dyes and Pigments, Vol. 94, No. 3, 2012, pp. 512-524. doi:10.1016/i.dyepig.2012.02.014

[13] T. Wilke and K. Kleinermanns, to be published, 2012.

[14] T. Ohno, K. Fujihara, K. Sarukawa, F. Tanigawa and M. Matsumura, "Splitting of Water by Combining Two Photocatalytic Reactions through a Quinone Compound Dissolved in an Oil Phase," Zeitschrift für Physikalische Chemie, Vol. 213, No. 2, 1999, pp. 165-174. doi:10.1524/zpch.1999.213.Part 2.165

[15] A. L. Rogach, A. Kornowski, M. Gao, A. Eychmüller and H. Weller, "Synthesis and Characterization of a Size Series of Extremely Small Thiol-Stabilized CdSe Nanocrystals," The Journal Of Physical Chemistry B, Vol. 103, No. 16, 1999, pp. 3065-3069. doi:10.1021/jp984833b

[16] G. A. Martínez-Castañón, M. G. Sánchez-Loredo, J. R. Martínez-Mendoza and F. Ruiz, "Synthesis of CdS Nanoparticles: A Simple Method in Aqueous Media," Azojomo, Vol. 1, No. 1, 2005, pp. 1-2. doi:10.2240/azojomo0170

[17] J. Yu, X. Zhao, J. Du and W. Chen, "Preparation, Microstructure and Photocatalytic Activity of the Porous $\mathrm{TiO}_{2}$ Anatase Coating by Sol-Gel Processing", Journal of SolGel Science and Technology, Vol. 17, No. 2, 2000, pp. 163-171. doi:10.1023/A:1008703719929

[18] T. Wilke, M. Schneider and K. Kleinermanns, “1,4-Hydroquinone is a Hydrogen Reservoir for Fuel Cells and Recyclable via Water Splitting," 2012. 


\section{Appendix}

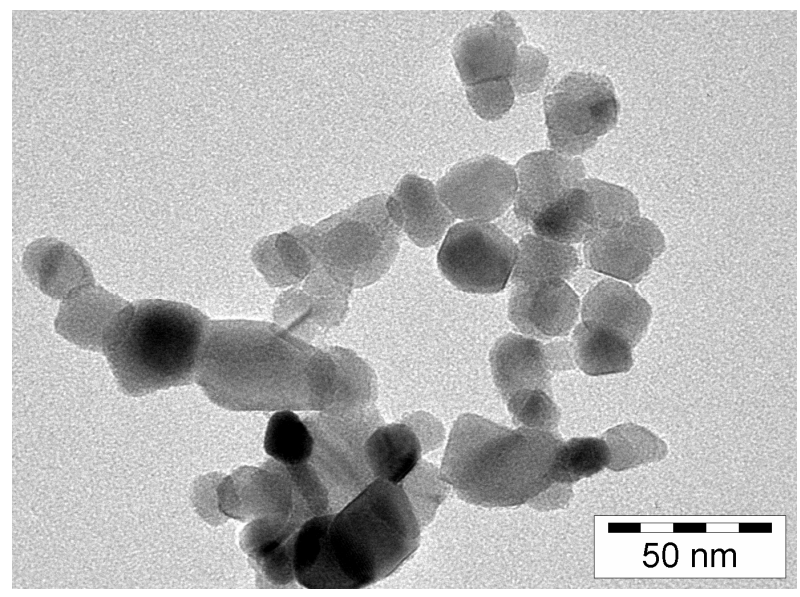

Figure SI1. TEM image of $\mathrm{TiO}_{2}$ nanoparticles with an average size of $21 \mathrm{~nm}$ obtained from Evonik (Aerosil $\mathrm{TiO}_{2}$ P-25). It consists of a mixture of $80 \%$ anastase and $20 \%$ rutile with a specific surface area of approximately $50 \mathrm{~m}^{2} / \mathrm{g}$.

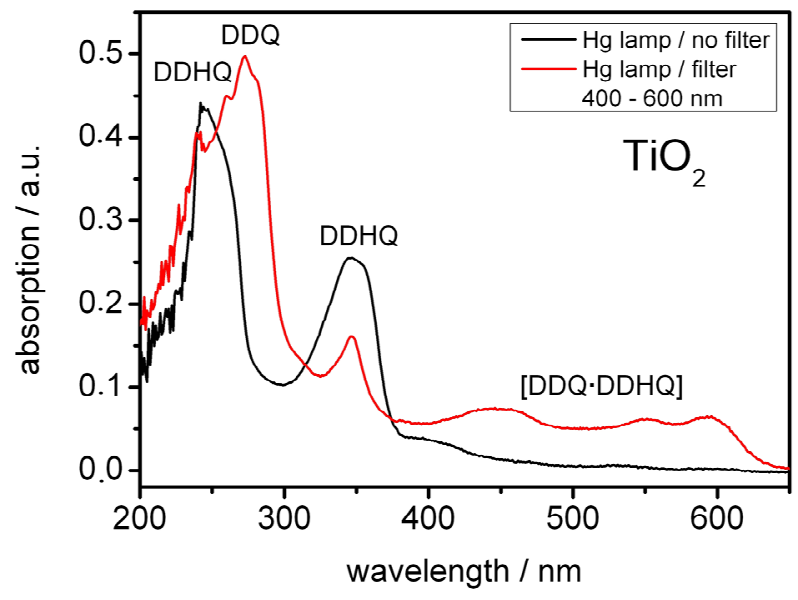

Figure SI2. Water splitting by $\mathrm{TiO}_{2}$ nanoparticles as photocatalyst. See Figure 5(a) for detailed explanation.

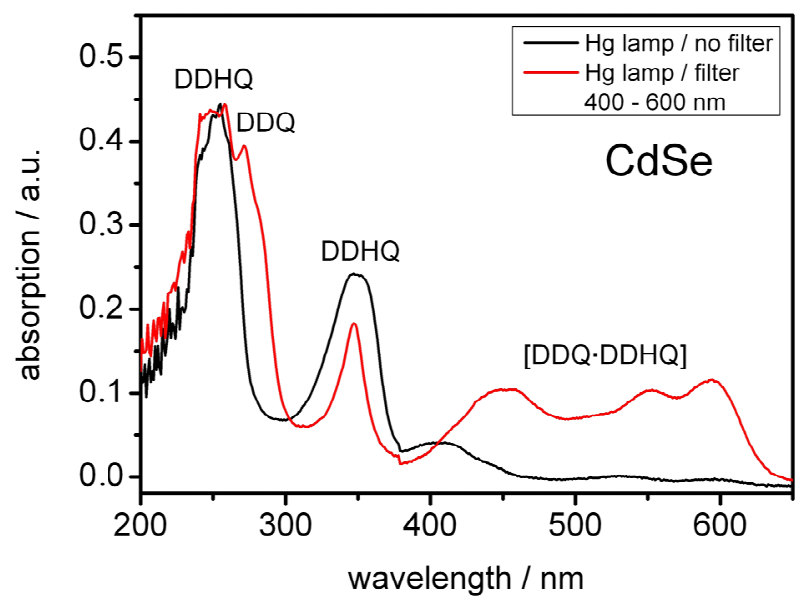

Figure SI3. Water splitting by CdSe nanoparticles as photocatalyst. See Figure 5(a) for detailed explanation.

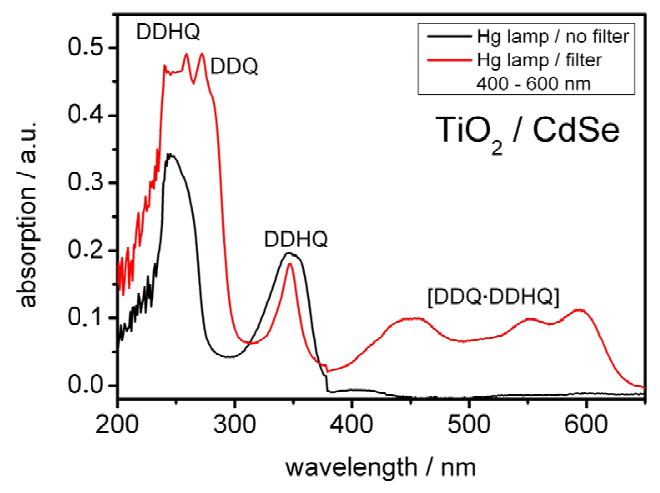

Figure SI4. Water splitting by $\mathrm{TiO}_{2} / \mathrm{CdSe}$ nanocomposits as photocatalyst. See Figure 5(a) for detailed explanation.

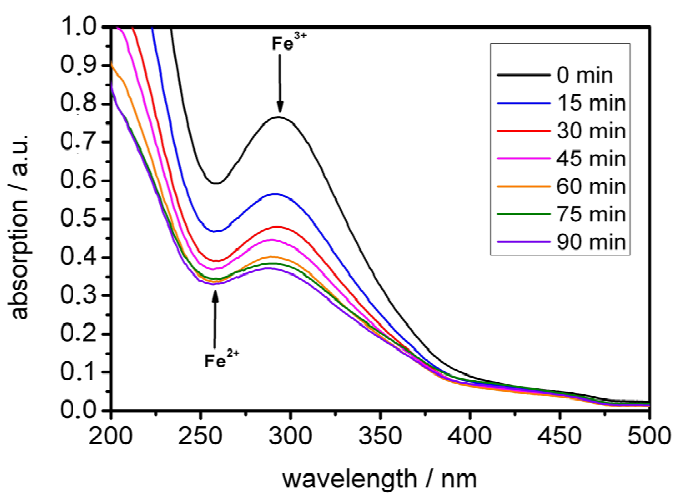

Figure SI5. Tracking of the electron transport process for $\mathrm{TiO}_{2}$ irradiated with the unfiltered $\mathrm{Hg}$ lamp. Presented are UV-Vis spectra of the aqueous phase registered over $90 \mathrm{~min}$. The absorption range of $\mathrm{Fe}^{3+}$ and $\mathrm{Fe}^{2+}$ are indicated by arrows. A rapid decrease of the $\mathrm{Fe}^{3+}$ concentration can be observed while the increasing absorption of $\mathrm{Fe}^{2+}$ is an evidence of the electron transport process.

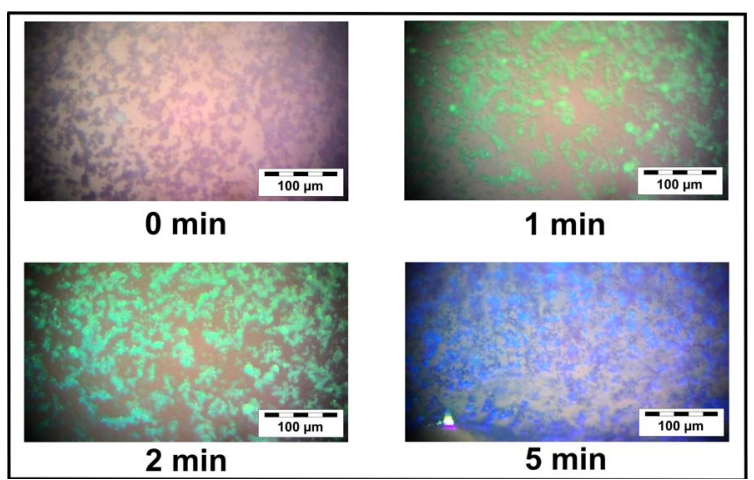

Figure SI6. Visual detection of the electron transfer process via a simple dye reaction. By addition of potassium ferrocyanide(III) to a suspension of $\mathrm{TiO}_{2}$ nanopowder in water the $\mathrm{Fe}^{2+}$ formed during the irradiation is trapped by the ferrocyanide and intense coloured Prussian blue $\mathrm{K}\left[\mathrm{Fe}^{\mathrm{III}} \mathrm{Fe}^{\mathrm{II}}(\mathrm{CN})_{6}\right]$ is formed on the surface of the $\mathrm{TiO}_{2}$ aggregates. The green and turquoise colour visible after the first two minutes is based on the mixture of the yellow-orange colour of remaining $\mathrm{FeCl}_{3}$ and the blue colour of already formed Prussian blue. 